\author{
Oliver Drognitz \\ Xuemei Liu \\ Robert Obermaier \\ Hannes Neeff \\ Ernst von Dobschuetz \\ Ulrich Theodor Hopt \\ Stefan Benz
}

\title{
Ischemic preconditioning fails to improve microcirculation but increases apoptotic cell death in experimental pancreas transplantation
}

\section{Transpl Int (2004) 17:317-324}

The legend of Fig. 3 did not wholly match the figure.

The correct legend is given here.

Fig. $3 \mathrm{Gel}$ electrophoresis of DNA samples extracted from pancreatic tissue after experimental pancreas transplantation. Pancreatic tissue subjected to $6 \mathrm{~h}$ of cold ischemia and subsequently to $2 \mathrm{~h}$ of reperfusion displayed a characteristic laddering pattern of 180-bp DNA fragments suggestive of apoptosis (lanes $P T x$ and $P T x \& I P C$ ). The laddering pattern was expressed most clearly in pancreatic tissue subjected to IPC prior to transplan- tation (lane $P T x \& I P C$ ), whereas banding of grafts of group Tx without IPC was less pronounced (lane $P T x)$. No DNA laddering was found in pancreatic tissue of animals that did not undergo transplantation (lane Control). Leftmost lane: positive control from the kit

O. Drognitz $(\bowtie) \cdot X$. Liu

R. Obermaier $\cdot$ H. Neeff

E. von Dobschuetz - U. T. Hopt

S. Benz

Department of General and Digestive Surgery,

University of Freiburg,

Hugstetter Strasse 55,

79106 Freiburg im-Bresigau, Germany

E-mail: oliverdrognitz@web.de

Tel.: + 49-761-2702806

Fax: +49-761-2702804 